Маллаева М.И., Ниналалова Ф.И. Современные проблемы развития отраслей социальной сферы малых городов Дагестана: анализ и пути решения

УДК 332.1

DOI: $10.21779 / 2500-1930-2016-31-4-55-62$

\title{
М.И. Маллаева, Ф.И. Ниналалова
}

\section{Современные проблемы развития отраслей социальной сферы малых городов Дагестана: анализ и пути решения}

Дагестанский государственный университет; Россия, 367001, г. Махачкала, ул. М. Гаджиева, 43a; madimal@mail.ru

Настоящее исследование посвящено анализу ключевых отраслей социальной сферы малых городов Республики Дагестан. На основе изучения обширного статистического материала установлены факторы, влияющие на миграционные процессы, проанализировано состояние учреждений образования, здравоохранения, объектов социально-бытовой инфраструктуры. Выявлен ряд проблемв указанных сферах: низкий абсолютный и относительный (в сравнении с другими отраслями, а также с аналогичными сферами крупных городов) уровень оплаты труда,техническая отсталость инфраструктурных объектов, недостаточный объем услуг, предоставляемых населению. Намечены важнейшие направления развития малых городов.

Ключевые слова: малье города, отрасли социальной сферы, миграционные проиессы, сочиально-бытовая инфраструктура, городская культура, муниципальныле учреждения, финансовая поддержка.

Актуальность настоящего исследования определяется важностью роли малых городов, тех функций, которые они выполняют в структуре расселения. Между тем, несмотря на очевидные преимущества малых городских поселений экологического и эргономического характера,условия проживания в российских малых городах зачастую неблагоприятны. Это обусловило необходимость проведения настоящего исследования, целью которого явилось изучение важнейших проблем социальной сферы малых городов Республики Дагестан.

В России малыми городами считаются населенные пункты с населением до 50 тыс. человек [1, с. 264]. Значительное количество таких поселений, те особые функции, которые они выполняют в структуре расселения страны, а также огромный пласт проблем, с которыми сталкиваются жители малых городов, определяют и необходимость исследований в данной области.

Современные малые города зачастую формируются как промышленные, аграрные либо агропромышленные центры сельских районов, продукция которых в основном предназначена для переработки на предприятиях административных центров [2].

Большинство малых городов формировались как административные, социальнокультурные или производственные центры. Практически утратив свое первоначальное значение, тем не менее, данная категория населенных пунктов сохранила сегодня ряд преимуществ перед крупными городами: это более благоприятная экологическая обстановка, наличие свободных территорий для дальнейшего освоения, шаговая доступность места работыи объектов социально-бытовой инфраструктуры, и т. д. Кроме того, в малых городах сохранились местные традиции, историческое и культурное наследие [3, с. 91]. 
Маллаева М.И., Ниналалова Ф.И. Современные проблемы развития отраслей социальной сферы малых городов Дагестана: анализ и пути решения

Однако имеющиеся преимущества не могут компенсировать огромное количество проблем, мешающих их социально-экономическому развитию, среди которых наиболее существенными являются:

- ограниченность экономического потенциала, что осложняет привлечение квалифицированных кадров и создание рабочих мест;

- низкий уровень благоустройства городов, однообразие и унылость их архитектурного облика $[4$, с. 102];

- недостаточное развитие объектов социальной и бытовой инфраструктуры;

- неразвитость городской культуры.

Эти факторы способствовали активному миграционному оттоку населения, его естественной убыли, характерной для подавляющего числа регионов страны. Заметно меняющаяся демографическая ситуация, проявляющаяся в изменении половозрастной структуры населения, показателях рождаемости, смертности и естественного прироста, также оказывает влияние на социально-экономическое развитие городов и районов.

По данным официальной статистики, в РФ малые города составляют порядка 70 \% общего количества населенных пунктов. В то же время численность населения не коррелирует с этим показателем: так, если по Республике Дагестан принять, что малые города составляют $40 \%$ от общегочисла городов ${ }^{1}$, то удельный вес жителей малых городов (136617 человек) составляетчуть более $10 \%$ от численности городского населения республики (1345209 человек) и еще меньше - от общей численности населения республики (4,5\%) (см. таблицу 1$)$.

Одной из наиболее острых проблем малых городов остается проблема миграции - оттока населения в крупные города и агломерации. При исследовании вопросов социально-экономического развития малых городов важно учитывать демографические процессы. Это позволит выявить главные«болевые точки» и определить меры, необходимые для оздоровления демографической ситуации.

Миграционные процессы вызваны неблагоприятными в целом условиями для реализации трудового и всего человеческого потенциала, характерными для малых городов [5]. Дагестан в этом смысле также не является исключением, имея отрицательное сальдо миграции за 2015 год в количестве 13390 человек. В разрезе малых городов данный показатель существенно разнится, при этом статистика демонстрирует его положительную величину для г. Кизилюрт (см. таблицу 1).

Таблица 1

Численность населения и миграционные процессы в малых городах Республики Дагестан, 2015г.

\begin{tabular}{|l|c|c|c|c|}
\hline & $\begin{array}{c}\text { Численность } \\
\text { населения }\end{array}$ & $\begin{array}{c}\text { Число } \\
\text { прибывших }\end{array}$ & $\begin{array}{c}\text { Число } \\
\text { выбывших }\end{array}$ & $\begin{array}{c}\text { Сальдо } \\
\text { миграции }\end{array}$ \\
\hline Республика Дагестан & 3015700 & 44235 & 57625 & -13390 \\
\hline Кизляр & 50845 & 1346 & 1761 & -418 \\
\hline
\end{tabular}

${ }^{1}$ Согласно данным таблицы 1 , г. Кизляр несколько выходит за рамки малого города. Однако численность его населения имеет скорее пограничное значение, а если принять во внимание такой фактор, как миграция, отрицательное сальдо которой по данным этой же таблицы составило на начало 2016г. 418 человек, то это вполне может способствовать в ближайший год-два некоторому снижению численности населения, постоянно проживающего в Кизляре, до 50 тыс.человек.

${ }^{2}$ Социально-экономическое положение территориальных округов Республики Дагестан за 2015г. (бюллетень). - Махачкала: Росстат, 2016. 
Маллаева М.И., Ниналалова Ф.И. Современные проблемы развития отраслей социальной сферы малых городов Дагестана: анализ и пути решения

\begin{tabular}{|l|c|c|c|c|}
\hline \hline Кизилюрт & 46547 & 1464 & 1238 & 226 \\
\hline Дагестанские Огни & 28887 & 779 & 1017 & -238 \\
\hline Южно-Сухокумск & 10338 & 289 & 342 & -53 \\
\hline
\end{tabular}

Несмотря на отток населения за пределы республики, в большинствегородов Дагестана динамика численности населения имеет положительный характер в течение ряда последних лет. Это можно объяснить, скорее всего, тем фактом, что Республика Дагестан остается одним из немногих субъектов Российской Федерации, в котором обеспечивается естественный прирост населения, обусловленный тем, что уровень рождаемости превышает уровень смертности. Эта тенденция в целом характерна и для малых городов. Так, по данным официальной статистики, коэффициент естественного прироста населения для городов Дагестана составляет в среднем 12,9 при разрыве между наибольшим - 15,3 и наименьшим - 7,1 значениями более чем в 2раза.

Среди мигрантов преобладает возрастная группы 20-39 лет, т. е. наиболее трудоактивная часть населения. Очевидно, что при этом меняется возрастной состав населения: сокращается доля молодежи и увеличивается число лиц пожилого возраста. Кроме того, к причинам миграции могут относиться низкий уровень жизни и неблагоприятные условия в малых городах республики. Так, среднемесячная заработная плата одного работающего жителя значительно ниже аналогичного показателя в крупном городе (см. таблицу 2), что на фоне нехватки рабочих мест усиливает миграционный отток [6].

Например, самая высокая среднемесячная заработная плата работников крупных и средних предприятий (26 576 рублей - г. Махачкала) почти везде большесамой низкой (13 302 рубля - г. Дагестанские Огни). По другим организациям складывается аналогичная картина.

Таблица 2

Сравнительная характеристика уровней оплаты труда работников крупного города (Махачкала) и малых городов Республики Дагестан, руб., 2015 г. ${ }^{1}$

\begin{tabular}{|c|c|c|c|c|c|c|}
\hline \multirow[t]{2}{*}{$\begin{array}{l}\text { Населенный } \\
\text { пункт }\end{array}$} & \multicolumn{2}{|c|}{$\begin{array}{l}\text { Среднемес. на- } \\
\text { численная зар- } \\
\text { плата работни- } \\
\text { ков }\end{array}$} & \multirow{2}{*}{$\begin{array}{l}\text { Крупных } \\
\text { и сред- } \\
\text { них } \\
\text { предпри- } \\
\text { ятий }\end{array}$} & \multirow{2}{*}{$\begin{array}{l}\text { Муници- } \\
\text { пальных } \\
\text { учрежд. } \\
\text { дошк.обр } \\
\text { азования }\end{array}$} & \multirow{2}{*}{$\begin{array}{l}\text { Муни- } \\
\text { цип. об- } \\
\text { щеобр. } \\
\text { учрежде- } \\
\text { ний }\end{array}$} & \multirow{2}{*}{$\begin{array}{l}\text { Муницип. } \\
\text { учрежд. } \\
\text { культуры } \\
\text { и искус- } \\
\text { ства }\end{array}$} \\
\hline & руб. & $\begin{array}{l}\text { В \% } \quad \text { к } \\
2014 \text { г. }\end{array}$ & & & & \\
\hline Махачкала & 26804,6 & 100,7 & 26576,5 & 10095,8 & 18134,5 & 14363,7 \\
\hline Кизляр & 21280,5 & 110 & 19710,7 & 11592,6 & 17821,2 & 14557,5 \\
\hline Кизилюрт & 21575 & 101,2 & 18273,7 & 11372,8 & 16512 & 12454 \\
\hline Дагестанские Огни & 14378,7 & 100,7 & 13302,8 & 8660,2 & 13846,1 & 11157,6 \\
\hline Южно-Сухокумск & 19090,6 & 103,5 & 15630,7 & 11360,9 & 15328,0 & 11943,9 \\
\hline
\end{tabular}

Если проанализировать значения заработной платы в муниципальных учреждениях республики, то самые низкие показатели будут у дошкольных организаций и учреждений культуры, а наиболее высокие - у работников крупных и средних предприятий. Так, уровень самой высокой заработной платы, которую получают работники

${ }^{1}$ http://dagstat.gks.ru. 
Маллаева М.И., Ниналалова Ф.И. Современные проблемы развития отраслей социальной сферы малых городов Дагестана: анализ и пути решения

крупных предприятий, в г. Махачкале превышает значение самой низкой заработной платы, получаемой работниками дошкольных учреждений в г. Дагестанские Огни, в 3,1 раза. Подобная дифференциация оплаты труда способствует неравенству в доходах, снижению престижности работы в учреждениях дошкольного образования и культуры и в целом меняет структуру занятости населения.

Ситуация с занятостью населения является одной из наиболее острых проблем малых городов. Среди основных причин напряженной ситуации на рынке труда можно назвать:

- высокую (в сравнении с другими регионами страны) рождаемость, естественный прирост населения;

- значительный удельный вес молодежи. Данный фактор особенно ярко проявляется в г. Дагестанские Огни, и здесь же отмечается наиболее высокое значение показателя зарегистрированной безработицы - 6,6 \% в 2014 году, что более чем в 30 раз выше аналогичного показателя в г. Махачкале $(0,2 \%)$.

Одной из важнейших сфер непроизводственного характера является жилищнокоммунальное хозяйство.

Так, за период с 2010 по 2014 годы общая площадь жилых помещений увеличилась во всех городах республики. Например, на $2 \%$ в г. Кизляр и до $32 \%$ - в г. Каспийск. При этом площадь ветхого и аварийного жилья, которое в среднем по республике в 2010 году составляло $15 \%$ от общего жилого фонда, к 2015 году практически не уменьшилась, за исключением г. Махачкалы -на 87 \%(до 0,7 \% - в 2014г.). По данным Дагстата, больше всего ветхого и аварийного жильяв г. Кизляре: удельный вес такого жилья в общей площади жилых помещений составляет 47, 6 \%.

Вот основные проблемы сферы ЖКХ, наиболее характерные для малых городов [7, c. 39]:

- высокий износ всех сетей (водопроводных, газопроводных и др.);

- значительный удельный вес зданий, требующих капитального ремонта, а в ряде случаев - и сноса;

- большое число жителей, находящихся в очереди на получение жилья.

Довольно удручающая ситуация сложилась в части качества помещений, в которых располагаются дошкольные образовательные учреждения. Так, доля ветхих и требующих капитального ремонта помещений составляет в среднем $55 \%$, колеблясь от 25 \% в г. Кизилюрте и до 67 \% - в городах Дагестанские Огни и Южно-Сухокумск ${ }^{1}$.

По результатам анализа статистических данных, больше всего проблем в сфере дошкольного образования.

Помимо проблем с помещениями, можно выделить еще ряд других, не менее важных:

- нехватка мест для детей. Об этом свидетельствуют данные таблицы 3: практически по всем малым городам республики (за исключением г. Южно-Сухокумск) число детей, стоящих в очереди на получение места, превышает количество детей, посещающих детские учреждения;

- низкий уровень оплаты труда работников детских дошкольных учреждений. Так, по данным Росстата, средняя заработная плата в этих учреждениях ниже заработной платы работников крупных и средних предприятий в 1,5-2 раза (см. таблицу 2).

\footnotetext{
${ }^{1}$ http://dagstat.gks.ru. 
Маллаева М.И., Ниналалова Ф.И. Современные проблемы развития отраслей социальной сферы малых городов Дагестана: анализ и пути решения

Таблица 3

Показатели развития учреждений образования (на начало 2015 г.) $)^{1}$

\begin{tabular}{|l|c|c|c|c|c|c|c|c|}
\hline \multicolumn{1}{|c|}{$\begin{array}{c}\text { Населенный } \\
\text { пункт }\end{array}$} & \multicolumn{4}{|c|}{ Дошкольные учреждения } & \multicolumn{2}{c|}{$\begin{array}{c}\text { Общеобразователь- } \\
\text { ные учреждения }\end{array}$} \\
\hline & $\begin{array}{c}\text { число } \\
\text { учр. }\end{array}$ & $\begin{array}{c}\text { число } \\
\text { мест }\end{array}$ & $\begin{array}{c}\text { число } \\
\text { детей }\end{array}$ & $\begin{array}{c}\text { число } \\
\text { стоящих } \\
\text { в очер. }\end{array}$ & $\begin{array}{c}\text { Обесп. } \\
\text { мест. }\end{array}$ & $\begin{array}{c}\text { число } \\
\text { днев. } \\
\text { учр. }\end{array}$ & $\begin{array}{c}\text { число } \\
\text { мест }\end{array}$ & $\begin{array}{c}\text { число } \\
\text { детей }\end{array}$ \\
\hline Кизляр & 15 & 2758 & 2663 & 2352 & 447,4 & 11 & - & 6918 \\
\hline Кизилюрт & 11 & 1400 & 1796 & 3333 & 323,3 & 8 & - & 5807 \\
\hline Дагестанские Огни & 6 & 900 & 1301 & 1555 & 268,1 & 9 & 3708 & 4825 \\
\hline Южно-Сухокумск & 3 & 370 & 512 & 151 & 495,3 & 5 & 1380 & 1440 \\
\hline
\end{tabular}

В системе дошкольного образования необходимо развивать новые формы, создавать группы различных направлений деятельности с детьми, частные дошкольные учреждения, активизировать строительство детских садов в соответствии с установленными нормативами.

Тем не менее, развитие образования является сегодня одним из главных приоритетов социально-экономической политики городов, именно данной сфере оказывается значительная финансовая поддержка. На сегодняшний день расходы муниципальных бюджетов на развитие сферы образования в городах республики имеют наибольший удельный вес в общей структуре расходов на социальную сферу. По данным таблицы 4 можно заметить, что, в отличие от других направлений, расходы на образование за период с 2010 по 2015 годы значительно увеличились: от 1,6 раз - в городах Дагогни и Южно-Сухокумск и до 3,9 раз - в городах Кизилюрт и Кизляр.

Расходы бюджета на социальную сферу, млн руб. ${ }^{2}$

Таблица 4

\begin{tabular}{|l|c|c|c|c|c|c|c|c|c|c|}
\hline \multirow{2}{*}{$\begin{array}{c}\text { Населенный } \\
\text { пункт }\end{array}$} & \multicolumn{3}{|c|}{ ЖКХ } & \multicolumn{2}{|l|}{ Образование } & \multicolumn{2}{l|}{$\begin{array}{l}\text { Физкульту- } \\
\text { ра и спорт }\end{array}$} & \multicolumn{2}{l|}{$\begin{array}{l}\text { Культура, } \\
\text { СМи }\end{array}$} & \multicolumn{2}{l|}{$\begin{array}{l}\text { Социаль- } \\
\text { ная пика } \\
\text { тика }\end{array}$} \\
\cline { 2 - 12 } & 2010 & 2015 & 2010 & 2015 & 2010 & 2015 & 2010 & 2015 & 2010 & 2015 \\
\hline Кизляр & 164,9 & 160,9 & 248,2 & 966,5 & 2,2 & 2,6 & 16,7 & 61,4 & 26,2 & 64,6 \\
\hline Кизилюрт & 241,6 & 77,7 & 238,2 & 935,4 & 1,6 & 23,7 & 10,8 & 34,7 & 49,7 & 48,6 \\
\hline $\begin{array}{l}\text { Дагестан- } \\
\text { ские Огни }\end{array}$ & 66,5 & 37,1 & 160,3 & 252,7 & 0,3 & 0,08 & 8 & 7,5 & 26,1 & 14,8 \\
\hline $\begin{array}{l}\text { Южно- } \\
\text { Сухокумск }\end{array}$ & 49,2 & 15,6 & 76,6 & 119,6 & 0,5 & 0,6 & 5,5 & 9,8 & 8 & 6,3 \\
\hline
\end{tabular}

1. Комплексная программа социально-экономического развития городского округа «город Избербаш» на 2016 год. Комплексная программа экономического и социального развития МО городской округ «г. Махачкала» на 2016-2018 гг. Комплексная программа экономического и социального развития МО «г. Хасавюрт» на 2015-2018 гг. Программа экономического и социального развития городского округа «город Дербент» на период до 2018 года. Программа комплексного социально-экономического развития МО «г. Кизляр» на 2015-2020 годы. Программа социально-экономического развития городского округа «г. Дагестанские Огни» Республики Дагестан на 2016-2019 гг. Программа социально-экономического развития ГО «г. Каспийск» на 2016 год и плановый период 2017 и 2018 годов. Программа социальноэкономического развития городского округа «город Южно-Сухокумск» на 2016-2018 годы.

${ }^{2}$ http://dagstat.gks.ru 
Маллаева М.И., Ниналалова Ф.И. Современные проблемы развития отраслей социальной сферы малых городов Дагестана: анализ и пути решения

Также серьезное внимание на муниципальном уровне уделяется развитию спорта и физическому воспитанию подрастающего поколения, активизации физкультурнооздоровительной и спортивно-массовой работы в учебных заведениях всех типов для сохранения и укрепления здоровья, формирования у молодежи стремления к физическому совершенству, здоровому образу жизни. Это способствует профилактике правонарушений и негативных явлений среди несовершеннолетних. Наблюдается положительная динамика числа спортивных учреждений, а также финансирования программ развития данной сферы. Так, в г. Кизилюрт объемы финансирования развития физкультуры и спорта за период 2010-2015 гг. увеличились в 14,8 раз. В этом городе значительно увеличилось число спортивных объектов - с 35 до 42 (см. таблицу 5).

В то же время уровень фактической обеспеченности от норматива объектами физической культуры и спорта оставляет желать лучшего. Например, обеспеченность спортивными залами от нормативной потребности составляет $0,004 \%$ 1.

Таблица 5

Показатели сферы социально-бытовых услуг, 2014 г.

\begin{tabular}{|c|c|c|c|c|c|c|c|c|}
\hline \multirow[t]{2}{*}{ Населенный пункт } & \multicolumn{2}{|c|}{$\begin{array}{l}\text { Число объек- } \\
\text { тов бытового } \\
\text { обслуживания }\end{array}$} & \multicolumn{2}{|c|}{$\begin{array}{l}\text { Число спор- } \\
\text { тивных со- } \\
\text { оружений, } \\
\text { ед. }\end{array}$} & \multicolumn{2}{|c|}{$\begin{array}{l}\text { Число учре- } \\
\text { ждений } \\
\text { культуры } \\
\text { досуга, ед. }\end{array}$} & \multicolumn{2}{|c|}{$\begin{array}{l}\text { Число биб- } \\
\text { лиотек, ед. }\end{array}$} \\
\hline & 2010 & 2014 & 2010 & 2014 & 2010 & 2014 & 2010 & 2014 \\
\hline Кизляр & 117 & 128 & 65 & 58 & 16 & 19 & 6 & 6 \\
\hline Кизилюрт & 64 & 49 & 35 & 42 & 5 & 3 & 6 & 6 \\
\hline Дагестанские Огни & 150 & 128 & 24 & 17 & 8 & 7 & 2 & 2 \\
\hline Южно-Сухокумск & 7 & 11 & 15 & 16 & 3 & 4 & 2 & 2 \\
\hline
\end{tabular}

Серьезные трудности испытывает сфера здравоохранения малых городов. Среди них главные - неукомплектованность врачебными кадрами (обеспеченность врачами в среднем не превышает $60 \%$ от норматива, а в поликлиниках этот показатель вдвое меньше), низкая обеспеченность койко-местами в больничных учреждениях (в среднем - 50 единиц на 10000 человек).

Несмотря на количественные характеристики, представленные в таблице 5, достаточно острой является потребность в объектах культурно-досугового типа. Так, обеспеченность библиотеками не превышает $40 \%$, учреждениями клубного типа $30 \%$.

Таким образом, в социальной сфере малых городов имеется огромное количество проблем, во многом связанных с отсутствием необходимого финансирования, следствием чего является техническая отсталость учреждений социальной сферы, нехватка квалифицированных кадров, неразвитость услуг в сфере дошкольного воспитания, медицинского обслуживания.

Для решения этих и других проблем малых населенных пунктов необходимо создать условия для их экономического, социального и культурного развития. К числу превентивных мер в данном направлении следует отнести формирование механизмов активизации собственных экономических возможностей в сочетании с политикой избирательной поддержки проблемных городов [8].

\footnotetext{
1 Программа комплексного социально-экономического развития муниципального образования «город Кизляр» на 2015-2020 годы. - Кизляр, 2015г. - С. 29.
} 
Маллаева М.И., Ниналалова Ф.И. Современные проблемы развития отраслей социальной сферы малых городов Дагестана: анализ и пути решения

Следует учитывать комплекс факторов внешней и внутренней среды, определяющих развитие каждого муниципального образования [9]. К ним относятся природная ситуация, уровень экономического развития региона и особенности менталитета проживающего населения.

Для повышения эффективности и устойчивости развития малым городам следует сконцентрировать свои усилия и ресурсы на возрождении и развитии своего потенциала, тех преимуществ, которые не только будут способствовать появлению новых производств, а с ними - и улучшению уровня жизни жителей, но и смогут обеспечивать в будущем выпуск конкурентоспособной продукции и услуг [10]. Учитывая особенности Республики Дагестан, особо следует выделить: 1) развитие туристических и рекреационных центров; 2) создание малых предприятий в сфере бытовых услуг; 3) возрождение народных промыслов.

\section{1. Зыкова Н.В., Хозяинова С.В. Малые города в системе социально-} экономического развития региона: современные тенденции и проблемы // Проблемы современной экономики. - 2011. - № 4 (40). - С. 264-266.

2. Роль и потенциал малых городов в устойчивом развитии системы расселения региона (на примере Воронежской области) // Архитектон: известия вузов. - 2010. № 30 .

3. Мешков В.А., Мешкова С.В., Мокроносов А.Г. Социально-экономическое развитие малых и средних городов Пермского края // Актуальные вопросы современной науки. - 2013. - № 1. - С. 91-98.

4. Чернышева Е.А., Кузнецов С.В. Проблемы устойчивого развития малых городов Российской Федерации // Экономика и управление. - 2012. - № 4. - С. 123-126.

5. Ильина И.Н. Качество городской среды как фактор устойчивого развития муниципальных образований // Имущественные отношения в Российской Федерации. 2015. - № 5 (164). - С. 69-82.

6. Кондратьев B.B. Роль мониторинга в обеспечении устойчивого развития социально-экономических процессов в регионе // Экономические науки. - 2012. - № 2 (87). - C. $168-171$.

7. Джаватов Д.К., Маллаева М.И. Кластеры в городской экономике: сущность, объективные предпосылки и перспективы развития // Вестник Дагестанского государственного университета. Сер. Общественные науки. - 2014. - № 5. - С. 34-45.

8. Соколова А.А. Современная дуалистическая модель развития малых городов РФ // Вестник ИНЖЭКОНа. - 2011. - № 3 (46).

9. Крупнов Ю.В. Заявление союза малых городов Российской Федерации «Сохраним России малые города». [Электронный ресурс]. / Ю. Крупнов. - Режим доступа: http://krupnov.livejournal.com/373648.html

10. Аблова Н.О. Перспективы социально-экономического развития малых и средних городов России: какой путь выбрать // Научные труды Вольного экономического общества России. - 2014. - Т. 181, № 2. - С. 98-100.

Поступила в редакиџюю 25 ноября 2016 г. 
Маллаева М.И., Ниналалова Ф.И. Современные проблемы развития отраслей социальной сферы малых городов Дагестана: анализ и пути решения

UDC 332.1

DOI: $10.21779 / 2500-1930-2016-31-4-55-62$

Socio-demographic problems of small towns in Dagestan: analysis and solutions

\section{M.I. Mallayeva, F.I. Ninalalova}

Dagestan State University; Russia, 367001, Makhachkala, M. Gadzhiyev st., 43a; madimal@mail.ru

The present study focuses on the analysis of key sectors of the social sphere of small towns of the Republic of Dagestan. On the basis of extensive statistical material factors influencing migration processes areinstalled, the current state of educational institutions, health facilities and social infrastructure is analysed. Tendencies of development of these areas: a low absolute and relative (compared with other industries, as well as with similar areas of large cities) level of remuneration, technical backwardness of infrastructures, lack of public services volume provided. The authors of the article outline major directions in the development of small towns in Dagestan.

Keywords: small towns, social sector, migration, social infrastructure, urban culture, municipal institutions, financial support.

Received 25 November, 2016 